\title{
Dynamic Simulation Analysis of Greenhouse Gas Emission Reduction in Hebei Province
}

\author{
Guo-Feng ZHANG ${ }^{1, a}$, Hui-Min LI ${ }^{2, b,{ }^{*}}$, Xiao-Ying MA ${ }^{3, c}$, Li-Xin SUN ${ }^{4, d}$, Zhen-Ying \\ $\mathrm{YU}^{5, \mathrm{e}}$, Nan-Nan $\mathrm{CAO}^{6, \mathrm{f}}$ \\ ${ }^{1}$ Hebei GEO University, China \\ ${ }^{2}$ Inner Mongolia University Of Technology, China \\ ${ }^{3}$ Hebei GEO University, China \\ ${ }^{4}$ Hebei GEO University, China \\ ${ }^{5}$ Hebei GEO University, China \\ ${ }^{6}$ Hebei GEO University, China \\ a zgfjjgl@163.com ,bhminglhw@163.com, c tongzzi@163.com, ${ }^{\mathrm{d}}$ sunlixin@sjzue.edu.cn, \\ eyuzhenying@sjzue.edu.cn, ${ }^{\mathrm{f}} \mathrm{c}$ coonannan@sjzue.edu.cn
}

Key words: dynamic optimization simulation, prediction, clean energy, model

\begin{abstract}
With the rapid growth of economy and population in Hebei Province, energy consumption and greenhouse gas emissions have increased year by year, and environmental problems have become increasingly prominent. How to achieve rapid economic growth under the constraints of the environment is the Hebei provincial government to solve the problem. Based on the material, energy, value balance and input-output model, this paper builds a comprehensive dynamic simulation model of social economy, greenhouse gas emission and energy utilization.
\end{abstract}

\section{Introduction}

In recent years, rapid economic development in Hebei Province, the irrational phenomenon of industrial structure has become increasingly prominent, air quality problems continue to deteriorate. 2005 - 2012, Hebei Province, the economic growth rate remained at around 10\%, greenhouse gas emissions of more than 700 million tons. "13th Five-Year Plan" energy plan pointed out that Hebei Province 2015-2020 unit GDP energy consumption fell more than 18\%, China in the "Paris carbon dioxide reduction agreement" in 2020 than the 2005 greenhouse gas emissions by $40 \%-45 \%$. Many scholars have done research on greenhouse gas emission reduction in Hebei Province. Although many achievements have been made, the existing problems cannot be ignored. First, the lack of greenhouse gas emission reduction research model and forecast research; Second, greenhouse gas emission reduction research for qualitative research, its policies and recommendations are not operational. In order to solve the above two problems, this paper preliminarily creates a dynamic optimization comprehensive evaluation model of the impact of clean energy on the environmental economy. Through the dynamic simulation experiment, the paper analyzes the influence of the development of clean energy on the environmental economy of Hebei Province, and puts forward the science of environmental improvement and economic development in Hebei Province Of the policy program.

\section{Model Construction}

Based on the present situation of social economy and environment in Hebei Province, this paper constructs a comprehensive evaluation model of dynamic optimization of economic impact on the basis of material, energy, value balance and input - output. The model includes a objective function and socio - economic, energy Balance, greenhouse gas emissions three sub-models. [1] 


\section{Objective Function}

The objective function of this paper is set to maximize the GRP of GDP in Hebei Province. The GRP value for each period is determined by the value of the industry $X^{n}$ and the value added. $v$ This paper divides the input-output table into three parts, namely, the primary industry, the secondary industry and the tertiary industry.

$$
G R P(t)=\sum_{n} v^{n} \cdot X^{n}(t) \quad n=(\text { ․ 3 })
$$

\section{Socioeconomic Model}

In order to optimize the environment and reduce greenhouse gas emissions, the government subsidizes the industry to adjust the industrial structure, where $K^{n}$ represents the accumulated capital of industry n; $\alpha^{n}$ represents the capital input and output of the industry than the reciprocal; $S^{n}$ represents the subsidy; $f^{n}$ stands for capital Depreciation rate; $I^{n}$ on behalf of the industry $\mathrm{n}$ investment.

$$
\begin{aligned}
& x^{n}(t) \leq \alpha^{n}\left\{k^{n}(t)-S^{n}(t)\right\} \\
& k^{n}(t+1)=k^{n}(t)+I^{n}(t+1)-f^{n} \cdot k^{n}(t)
\end{aligned}
$$

The development and utilization of new energy by the new energy power generation technology investment conversion coefficient $B^{k}\left(B^{p}\right)$ and the Hebei provincial government investment in new energy $I^{k}\left(I^{p}\right)$ decision; The management fee $M^{k}\left(M^{p}\right)$ is determined by the amount of electricity generated $W^{k}\left(S E^{p}\right)$ and the management cost conversion factor $\zeta^{k}\left(\zeta^{p}\right)$ which $\mathrm{k}$ said wind power technology, p said solar power technology. ${ }^{[2]}$

$$
\begin{array}{ll}
\Delta W^{k}(t+1)=I^{k}(t) \cdot B^{k} & k(=\text { D) } \\
\Delta S E^{p}(t+1)=I^{p}(t) \cdot B^{p} & p(=3) \\
G S(t)=\sum_{k}\left(I^{k}(t)+W^{k}(t) \cdot \zeta^{k}\right)+\sum_{p}\left(I^{p}(t)+S E^{p}(t) \cdot \zeta^{p}\right)
\end{array}
$$

According to the market balance requirements, the total output of each industry $X^{n}$ is greater than or equal to the final demand and the middle of the sum of investment, which $Q^{n}$ on behalf of the $\mathrm{n}$ industry input and output coefficient; $C$ on behalf of the total consumption; $\beta^{k}, \beta^{p}$, respectively, on behalf of the new wind power technology $\mathrm{k}$ and solar power generation technology $\mathrm{p}$ on the development of the industry impact coefficient; $e$ on behalf of the total net exports.

$$
X^{n}(t) \geq Q^{n} \cdot X^{n}(t)+C(t)+i^{n}(t)+\sum_{k} \beta^{k} I^{k}(t)+\sum_{p} \beta^{p} I^{p}(t)+e(t)
$$

\section{Energy Supply and Demand Module}

The total energy demand in this paper includes the demand for industrial production and final consumption, and the energy type is divided into six kinds, among which $E D_{j}^{n}$ and $F E C_{j}$ represent the demand coefficient of the jth energy caused by the nth industry and the final consumption respectively; $H Z$ represents Population; $\omega$ represents the per capita consumption coefficient. Hebei Province, the total energy supply TES is divided into energy production enterprises $E P S$, external transferred to the $E T E$, the new wind farm generated energy $W P E$ and new solar energy generated by the power of $W P E$.[3] 


$$
\begin{aligned}
& T E D(t)=\sum_{j}\left(\sum_{n} X^{n}(t) \cdot E D_{j}^{n}+C(t) \cdot F E C_{j}\right) \quad(j=1,2 \ldots 6) \\
& C(t+1)=\omega \cdot H Z(t+1) \\
& T E S(t)=\operatorname{EPS}(t)+\operatorname{ETE}(t)+\operatorname{WPE}(t)+\operatorname{SPE}(t) \\
& \operatorname{TED}(t) \leq \operatorname{TES}(t)
\end{aligned}
$$

\section{GHG Emissions Module}

Hebei Province, greenhouse gas emissions 95.125\% from the energy consumption, this selected greenhouse gases for the $\mathrm{CO} 2, \mathrm{~N} 2 \mathrm{O}$ and $\mathrm{CH}_{4}\left(b=1: \mathrm{CO}_{2} ; b=2: \mathrm{CH}_{4} ; b=3: \mathrm{N}_{2} \mathrm{O}\right)$, greenhouse gas emissions $T G G E$ is divided into industrial production of greenhouse gas emissions and the final consumption of greenhouse gas emissions, of which $E C_{j}$ that the first $\mathrm{j}$ of energy greenhouse gas emissions coefficient; $E C I$ on behalf of the emission intensity; $\checkmark$ that greenhouse gas unit GDP energy consumption decline coefficient.

$$
\begin{aligned}
& T G G E(t)=\left(\sum_{n} \sum_{j} X^{n}(t) \cdot E D_{j}^{n} \cdot E C_{j}+\sum_{j} C(t) \cdot F C G_{j} \cdot E C_{j}\right) \cdot \sum_{b} P C G^{b} \\
& T G G E(t+1) \leq T G G E(t) \cdot \delta \\
& E C I(t+1) \leq E C I(t) \cdot \varsigma
\end{aligned}
$$

\section{Data Sources and Scenarios}

\section{Data Sources}

The data sources include three countries: national publication, field investigation and hands-on calculation. Among them, the state published data include "Hebei Province Statistical Yearbook 2005-2015", "Hebei Province Environmental Status Bulletin 2005-2015", "National Energy Board", "National Statistical Yearbook 2005-2015", "Polaris power grid", " Five "energy planning," Paris Climate Change Agreement "; the other conducted a field study, from the Hebei Provincial Environmental Protection Bureau, Hebei Province Energy Bureau of Hebei Province, the greenhouse gas emissions data; according to the data collected in the model of the correlation coefficient Calculation, and finally complete the data collection work.

\section{Scenario Design}

This paper combines the "thirteen five" plan and the contents of the Paris agreement, the model is set to three scenarios. Scenario 1, 2, and 3 GHG emission reduction rates were $30 \%, 35 \%$ and $40 \%$ respectively. Three scenarios are implemented subsidized industrial structure adjustment and development of clean energy policy.

\section{Analysis of the Best Scenario}

The optimal situation of this paper is the change rate of greenhouse gas emission intensity, the total amount of economic change, the proportion of clean energy to total energy and the change of energy consumption intensity.

\section{Best Scenario Selection}

From the simulation results we can find that the three scenarios, the industrial structure has changed, the high energy consumption of the secondary industry output decreased, while the first and third industry output increased, in line with our expectations, three scenarios in clean energy accounted for And energy consumption intensity is not very different, have reached our goal, but the scenario of the economic average annual growth rate of the fastest. More in line with our expectations, as 
shown in Table 1.

Table 1 Simulation results

\begin{tabular}{|c|c|c|c|}
\hline Scenario & $\begin{array}{c}\text { Total economy } \\
\text { (trillions of dollars) }\end{array}$ & $\begin{array}{c}\text { Economic average } \\
\text { annual growth rate }\end{array}$ & $\begin{array}{c}\text { Energy intensity in 2030 (tons } \\
\text { of standard coal / million yuan) }\end{array}$ \\
\hline Scenario one & 61.23 & $2.58 \%$ & 0.46 \\
\hline Scenario two & 59.48 & $2.15 \%$ & 0.45 \\
\hline Scenario three & 57.88 & $1.17 \%$ & 0.45 \\
\hline
\end{tabular}

\section{Analysis of Economic Growth Trend under the Optimal Situation}

Based on the implementation of industrial restructuring policies and the implementation of new energy development policies, the total economic output of Hebei Province increased from 2.66 trillion in 2012 to 4.2 trillion in 2030, increasing trend, Hebei Province, the highest growth rate of $4.30 \%$, the lowest Growth rate of $0.79 \%$, the average annual growth rate of $2.58 \%$, as shown in Figure 1,2030 emission reduction targets under the economic growth slowdown, but the total economic growth year after year, to meet the requirements of sustainable development of environmental economy.

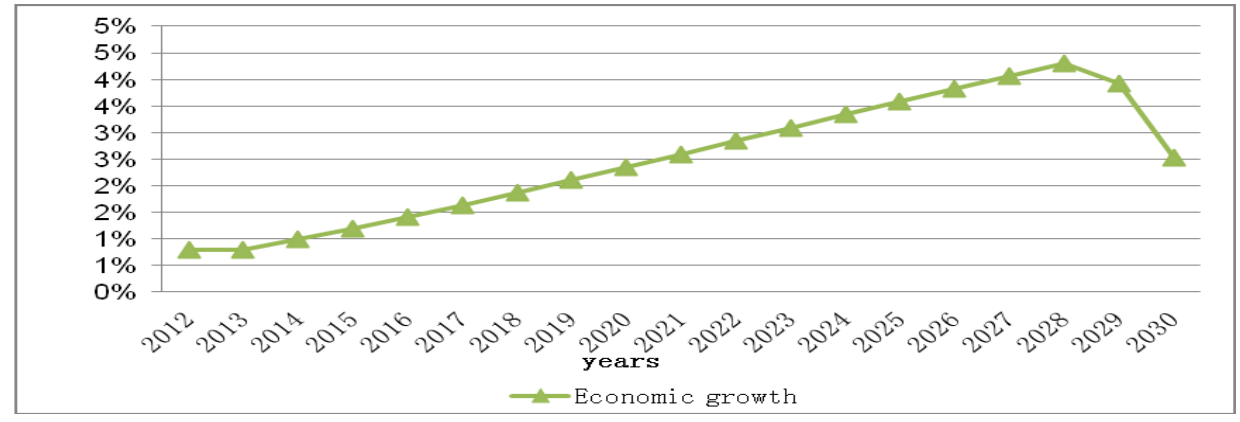

Figure 1 Hebei Province 2012-2030 economic growth

\section{Analysis of Total Energy and Structure in Optimal Scenario}

Due to environmental constraints and industrial restructuring, high energy consumption of the secondary industry accounted for a substantial decline in the proportion of one or three industries increased year by year, while the total economic growth continued under the premise of energy use decreased year by year, of which the use of coal The amount of energy reduction in the larger, by 2030 the total energy use reduced to 200 million tons of standard coal below, the total energy use reduction rate increased slightly in 2030, compared with 2012, a total reduction of $36 \%$. Clean energy accounted for the total energy from $0.73 \%$ in 2012 to $1.30 \%$ in 2030 , the proportion of coal decreased significantly, other energy accounted for an increase in the energy structure is greatly optimized, the environmental problems have been greatly improved, in line with Sustainable development of environmental economy.

\section{Environmental Improvement in the Best Scenario}

Through the implementation of industrial structure adjustment and the implementation of new energy development policies, greenhouse gas emissions significantly reduced in 2030, Hebei Province, the total greenhouse gas emissions 416,517,700 tons, less than the total emissions in 2012 to reduce the number of 167.4398 million tons, 2012 - 30\% reduction in greenhouse gas emissions during the 2030 period, and it is expected that greenhouse gas emissions will continue to decline after 2030 and the environmental conditions will be greatly optimized. 


\section{Analysis of Financial Subsidy in the Optimal Situation}

In order to realize the sustainable and healthy development of environmental economy, Hebei Province should vigorously develop the first and the third industry, especially the high value-added services (such as commerce, finance, etc.), 2012-2030 Subsidized primary industry 8.859 billion yuan, the second industry 370.788 billion yuan, the tertiary industry 34.654 billion yuan. The development and utilization of new energy is the key to environmental improvement, from the root causes to reduce greenhouse gas emissions. According to the results of the simulation experiment, 2012-2030 should subsidize wind power generation technology 501.6 billion yuan, solar power generation technology 4,213,546 billion yuan.

\section{Conclusion}

In this paper, the computer simulation software is used to simulate the energy saving and emission reduction process, and the dynamic optimization evaluation model is constructed. The influence of energy saving and emission reduction on the environmental economy is analyzed scientifically. In the best case, Hebei Province in the 2012-2030 annual economic growth rate of $2.58 \%$, greenhouse gas emission reduction of more than 30\%, energy intensity from 20121.14 tons of standard coal / million reduced to 20300.45 tons of standard coal / Million, clean energy accounted for from $0.73 \%$ in 2012 increased to $1.30 \%$ in 2030 . The experimental results show that the province needs to focus on the development of the first and tertiary industries, during the simulation to subsidize the secondary industry 370.788 billion yuan. To win the 2030 industry accounted for 2: 1: 7 . Vigorously develop the use of clean wind and solar energy, adjust the energy structure, 2012-2030 should subsidize wind energy 13564.39 billion yuan, solar energy 5016.39 billion yuan, to achieve economic growth on the basis of the expected emission reduction effect.

\section{Acknowledgements}

This work has been funded by Hebei Province Social Science Fund Project (Dynamic optimization simulation of haze formation mechanism and governance path in Hebei Province) funded, (HB16YJ019).

\section{References:}

[1] F Xu, N Xiang ,J Yan, L Chen, P Nijkamp .Dynamic simulation of China's carbon emission reduction potential by 2020. Letters in Spatial and Resource Sciences, 2015, 8 (1):15-27.

[2] Jungbluth N, Bauer C, Dones R, et al. Life cycle assessment for emerging technologies: case studies for photovoltaic and wind power [J]. Energy Supply, 2005, 10 (1): 1-11.

[3] Qian Zhou, Helmut Yabar, Takeshi Mizunoya, Yoshiro Higano. Exploring the potential of introducing technology innovation and regulations in the energy sector in China: a regional dynamic evaluation model. University of Tsukuba, Graduate School of Life and Environmental Sciences. 2016 112: 1537-1548. 